\title{
O ESTUDO DE IMPACTO DE VIZINHANÇA COMO INSTRUMENTO PARA O DESENVOLVIMENTO DA QUALIDADE DE VIDA URBANA
}

\section{THE IMPACT ASSESSMENT OF NEIGHBORHOOD AS A TOOL FOR DEVELOPMENT OF QUALITY OF URBAN LIFE}

\author{
Paulo Diego D’ Ovídio Silva ${ }^{1}$; José Augusto de Lollo² \\ ${ }^{1}$ Universidade Estadual Paulista, UNESP - Rio Claro, SP e Universidade Federal de \\ São Carlos, UFSCar, São Carlos, SP. E-mail p_dds@yahoo.com.br \\ ${ }^{2}$ Departamento de Engenharia Civil, Universidade Estadual Paulista, UNESP, Ilha \\ Solteira, SP. E-mail ja_lollo@yahoo.com
}

\begin{abstract}
RESUMO
O processo de urbanização trouxe para as cidades dois problemas graves: a exclusão social e a especulação imobiliária. No sentido de reverter a degradação do meio ambiente urbano, o Estatuto da Cidade - Lei Federal 10.257, promulgada em 10 de julho de 2001, cria os instrumentos necessários para planejar a cidade, de modo a promover a qualidade de vida dos cidadãos. Dentre os vários instrumentos estabelecidos na lei, surge o Estudo de Impacto de Vizinhança - EIV, um instituto fundamental para se evitar a implantação de empreendimentos ou atividades potencialmente causadoras de degradação à vizinhança imediata, ao meio ambiente urbano e à qualidade de vida urbana. Dessa maneira, o presente artigo discute o papel do EIV como ferramenta para a promoção da qualidade de vida nas cidades, uma vez que tal instituto está cada vez mais sendo utilizado pelos municípios no processo de ordenamento urbano.
\end{abstract}

Palavras-chave: Ambiente Urbano. Cidade. Impacto de Vizinhança. Estudo de Impacto de Vizinhança.

\begin{abstract}
The urbanization process has brought to cities are two serious problems: social exclusion and land speculation. To reverse the degradation of the urban environment, the City Statute - Federal Law 10.257, promulgated on July 10, 2001, creates the necessary tools to plan the city in order to promote quality of life of citizens. Among the various instruments established by law, there is the Impact of Neighborhood, an institute essential to avoid the deployment of developments or activities that have the potential to degrade the immediate neighborhood, the urban environment and quality of urban life. Thus, this article discusses the role of Impact of Neighborhood as a tool for enhancing the quality of life in cities, as this institute is increasingly being used by municipalities in urban planning process.
\end{abstract}

Key-words: Urban Environment. City. Neighborhood Impact. Neighborhood Impact Studies. 


\section{INTRODUÇÃO}

Surgida desde longa data, a cidade encontrou na agricultura irrigada, desenvolvida nas planícies dos grandes rios egípcios e mesopotâmicos a força motriz para seu crescimento, sendo a Revolução Agrícola considerada como o marco do surgimento citadino.

Séculos mais tarde, a cidade passou para sua fase moderna, onde a velocidade das relações urbanas aumentou desenfreadamente, fato inaugurado pela Revolução Industrial ocorrida na Inglaterra durante a segunda metade do século XVIII. Esta encerrou a transição entre feudalismo e capitalismo, a fase de acumulação primitiva de capitais e de preponderância do capital mercantil sobre a produção, promovendo a substituição das ferramentas pelas máquinas, assim como a o modo de produção doméstico pelo sistema fabril.

Atualmente, a cidade é um espaço público com relações privadas constitutivas. A publicização de alguns institutos mostra uma preocupação, entretanto, com a funcionalidade social desse espaço. Percebe-se que não existe uma distinção clara entre cidade e município, e que mesmo a cidade possui o âmbito urbano que lhe caracteriza, e um âmbito rural (BRITO e GÓIS, 2008).

De qualquer forma, o desenvolvimento urbano ordenado tem constituído importante desafio aos técnicos em planejamento, administradores públicos e políticos, frente à crescente conscientização e demanda da sociedade contra a degradação do meio ambiente, em prol de melhor qualidade de vida nas cidades (BARCELLOS e BARCELLOS, 2004).

Os autores afirmaram que as pressões exercidas por organizações não governamentais (ONGs) preocupadas com a proteção ambiental têm sido divulgadas com freqüência pela mídia, em todo o mundo. Afetada por crescente desemprego e deterioração da renda, dentre outras múltiplas variáveis, parcela representativa das populações urbanas de grandes cidades em países periféricos e semiperiféricos, dentre os quais o Brasil não é exceção, tem ocupado irregularmente terrenos urbanos e próprios nacionais, fixando-se até mesmo em áreas de proteção ambiental (APAs). O tema não é novo, mas tem adquirido relevância com o correr do tempo, particularmente nos últimos anos, em que as soluções de curto prazo divisadas, na maioria das vezes, ao invés de resolver o problema terminam por contribuir para seu agravamento (BROWN, 2003 apud BARCELLOS e BARCELLOS, 2004).

A qualidade da vida no meio urbano tem se tornado preocupação da população. Embora seja um conceito relativamente recente, a expressão qualidade de vida é, hoje em dia, utilizada frequentemente tanto ao nível da linguagem comum, como ao nível do discurso teórico, sendo um tema central em todas as análises e políticas de planejamento e de gestão do território, em particular das cidades.

Historicamente, esse conceito surge nos anos de 1960, onde prevalecia uma corrente essencialmente economicista que analisava o crescimento econômico das sociedades através da evolução dos sistemas de indicadores sociais, (como por exemplo, o PIB - Produto Interno Bruto), os quais estavam em fase de implantação e expansão. Esta medida, correspondendo ao montante de bens e serviços gerados e sendo assim, um indicador da riqueza produzida e distribuída, traduzia de forma global o crescimento econômico verificado, mas não contemplava diversos aspectos fundamentais que permitissem analisar o desenvolvimento de uma sociedade (SANTOS e MARTINS, 2002).

O conceito de qualidade de vida, como será discutido adiante, englobam diversos aspectos que se interligam, e que vão desde as questões materiais ligadas à satisfação das necessidades humanas básicas, até as questões imateriais (como a segurança e a participação cívica), desde aspectos objetivos até aspectos subjetivos, estes últimos relacionados com a percepção individual da qualidade de vida e do bem estar dos indivíduos, desde aspectos de natureza individual até aspectos de natureza coletiva. (VERONA, 2008)

De acordo com Moraes (2007), nas últimas décadas a preocupação com a qualidade de vida 
nas cidades têm se intensificado, haja vista que o adensamento populacional, sem o devido planejamento, tem gerado uma série de consequências negativas à vida urbana, tais como, enchentes, tráfego intenso de veículos, sobrecarga do transporte urbano e todo o tipo de poluição (ar, água e visual). Como afirma Milaré (2005, p.217) apud Moraes (2007):

\begin{abstract}
Os elevados índices de urbanização e, inversamente, os baixos níveis de urbanismo têm criado situações insustentáveis para o Poder Público e a coletividade. $\mathrm{O}$ inchaço doentio dos centros urbanos (aumento desregrado da população) não tem encontrado o contrapeso das estruturas urbanas necessárias (moradia, trabalho, transporte e lazer), gerando-se daí formas endêmicas de males urbanos. E - o que é pior - o fascínio das cidades e a concentração populacional crescem sem o necessário controle quantitativo e qualitativo desse crescimento.
\end{abstract}

Tal preocupação acabou por acirrar os debates acerca da falta de um planejamento urbano adequado, além de vincular a qualidade de vida citadina com a preservação e conservação ambiental.

O termo meio ambiente será entendido aqui, como as relações dos homens com a natureza para preservação dos recursos naturais em processos de desenvolvimento sustentável. Já o ambiente urbano pode ser entendido como o conjunto de relações dos homens com o espaço construído e a natureza nas aglomerações de população e de atividades humanas (MOREIRA, 1999).

De acordo com o referido autor, ao se considerar os aspectos naturais, paisagísticos e urbanísticos, o ambiente urbano pode ser descrito como o conjunto de relações dos homens com o espaço construído e com a natureza, em aglomerações de população e atividades humanas, constituídas por fluxos de energia e de informação para nutrição e biodiversidade; pela percepção visual e atribuição de significado às conformações e configurações da aglomeração; e pela apropriação e fruição (utilização e ocupação) do espaço construído e de recursos naturais.

As preocupações com a qualidade de vida urbana também geraram contendas voltadas ao desenvolvimento sustentável, onde o termo cidade sustentável passou a ser largamente empregado. Este termo é uma cidade que possui uma política de desenvolvimento urbano, de tal modo que promova medidas para proteger o meio ambiente natural e construído, garantindo a função social ambiental da propriedade na cidade (FERRAZ, 2006).

A sustentabilidade é um conceito complexo que envolve as dimensões ambiental, social, econômica e temporal dos processos urbanos. Admitir que o desenvolvimento sustentável passou a ser um componente fundamental do desenvolvimento urbano, significa a compatibilidade constitucional do desenvolvimento urbano, assegurando o direito das gerações atuais e futuras ao meio ambiente ecologicamente equilibrado (FERRAZ, 2006).

A avaliação de impactos no meio urbano devido à instalação e operação de empreendimentos não contemplados na legislação federal que prevê a realização de Estudos de Impacto Ambiental foi, durante algum tempo, um problema de difícil solução, uma vez que não havia legislação que disciplinasse o tema (LOLLO e RÖHM, 2005).

Durante o fim da década de 1980, surgiu o Projeto de Lei 181/89 elaborado pelo senador Pompeu de Souza, o qual originou o Estatuto da Cidade (EC). Sancionado em 2001, esse Estatuto foi um grande avanço no que concerne ao planejamento e ao desenvolvimento urbano, e trouxe consigo um instrumento para auxiliar a avaliação de impactos ambientais: o EIV (Estudo de Impacto de Vizinhança) (LOLLO e RÖHM, 2005). Dessa maneira, a Lei 10.257/2001 estabeleceu os princípios gerais para tal tipo de análise ao propor um conjunto de fatores a serem avaliados quando da realização do Estudo Prévio de Impacto de Vizinhança, definido, pela mesma lei, como instrumento fundamental para "[...] obter as licenças ou autorizações de construção, ampliação ou funcionamento [...]" dos empreendimentos (BRASIL, 2001). 
O Estatuto da Cidade, ao mesmo tempo em que oferece instrumentos para a reforma urbana, prescreve a sintonia entre a garantia do direito humano à moradia e o direito a esse meio-ambiente ecologicamente equilibrado nas cidades. Com a lei, as cidades brasileiras estão obrigadas a compatibilizar a gestão urbana e a gestão ambiental, por meio da integração de políticas de planejamento urbano, política habitacional e política ambiental (FERRAZ, 2006).

Sendo assim, o presente artigo procura demonstrar a importância do Estudo de Impacto de Vizinhança como instrumento para o desenvolvimento da qualidade de vida urbana.

\title{
2. O ESTUDO DE IMPACTO DE VIZINHANÇA COMO INSTRUMENTO PARA O PLANEJAMENTO URBANO
}

Conforme Floriano (2004), planejar é, talvez, a principal característica que distingue as atividades humanas daquelas de outros animais. Por ser racional, o homem pode analisar o que ocorreu em situações semelhantes para prever o que é necessário fazer no futuro, repetindo o que deu certo e evitando os erros do passado; a este processo de organizar previamente as atividades futuras com base no conhecimento do passado dá-se o nome de "planejamento".

Como afirmou Franco (2000) apud Zibordi e Cardoso (2005), as primeiras ideias do que seria o planejamento conhecido atualmente surgiram a partir das décadas iniciais do século XIX, com pensamentos utópicos e românticos para a época. Essas já vislumbravam a escassez de recursos, em um momento, em que era implementada a primeira revolução industrial, sob a égide do positivismo e do liberalismo econômico e que pressupunha a inesgotabilidade dos recursos da Terra.

Durante muito tempo, até o século XX, a maioria dos planos e planejamentos territoriais foi direcionada por uma visão positivista e progressista, baseada no crescimento ilimitado e na transferência de tecnologias. Para Deák (2010), no sentido estrito, planejamento é a formulação, mais ou menos explícita, da intervenção do Estado na produção e reprodução sociais, na dialética do Estado e do mercado. Segundo esse autor:

\begin{abstract}
O planejamento se desenvolve especialmente no estágio de desenvolvimento intensivo com a ampliação da atuação do Estado; a colocação do interesse coletivo em posição central na ideologia da social democracia ou do Estado de Bem-estar e a necessidade do ordenamento e estruturação das grandes aglomerações urbanas, inaugurando a gênese do planejamento urbano.
\end{abstract}

Como afirmou Saboya (2008), o planejamento surgiu como uma resposta aos problemas enfrentados pelas cidades, tanto aqueles não resolvidos pelo urbanismo moderno quanto aqueles causados por ele. A expressão "planejamento urbano" vem da Inglaterra e dos Estados Unidos, e marca mudança na forma de encarar a cidade e seus problemas.

O planejamento urbano é o processo de criação e desenvolvimento de programas que buscam melhorar ou revitalizar certos aspectos (como a qualidade de vida da população) dentro de uma dada área urbana (como cidades ou vilas); ou do planejamento de uma nova área urbana em uma dada região, tendo como objetivo propiciar aos habitantes a melhor qualidade de vida possível (RODRIGUES e FILHO, 2011).

Desta maneira, o planejamento urbano segundo um ponto de vista contemporâneo (e, em certa medida, pós-moderno), tanto enquanto disciplina acadêmica quanto como método de atuação no ambiente urbano, lida basicamente com os processos de produção, estruturação e apropriação do espaço urbano. A interpretação destes processos, assim como o grau de alteração de seu encadeamento, varia de acordo com a posição a ser tomada no processo de planejamento e principalmente com o poder de atuação do órgão planejador (RODRIGUES e FILHO, 2011). 
A partir do fenômeno urbanizatório, a cidade passa a ser foco de atenção, configurando-se como meio ambiente construído ou artificial. O momento histórico considerado é o da Revolução Industrial, com os fenômenos migratórios de êxodo rural. A cidade, no entanto, é anterior ao Estado, consistindo em uma modelo das organizações políticas atuais.

"A cidade era uma confederação", conforme menciona Coulanges (2004) apud Brito e Góis (2008), com vários grupos associados e estágios ou ritos de passagem, tendo por ponto integrador a religião comum, vivida na urbe. Segundo esses autores, várias famílias formavam a fratria, várias fratrias, a tribo, e diversas tribos a cidade. A organização parte do privado para o mais geral.

Como dinâmica própria, a cidade tem responsabilidades ambientais, visto ser um espaço ambiental, embora artificializado pela produção humana. A criação de deveres ambientais no corpo da Constituição aumenta a responsabilidade dos entes federativos, que repartem esse dever fundamental de cunho ambiental com a comunidade (BRITO e GÓIS, 2008). Ainda segundo esses autores, o artigo 225 da Constituição da República Federativa do Brasil (CRFB) prevê o direito de todos ao meio ambiente ecologicamente equilibrado, “(...) impondo-se ao poder público e à coletividade o dever de defendê-lo e preservá-lo para as presentes e futuras gerações" (BRASIL, 1988).

Lollo e Röhm (2005), apesar das bases históricas em instrumentos legais de proteção à flora e recursos hídricos cujas datas remontam a década de 1940, afirmaram que a legislação que trata de impactos ambientais no Brasil teve seu desenvolvimento efetivo a partir da década de 1980 . O estudo de impacto como critério para implantação de proposta de ocupação foi introduzido na legislação brasileira com a Lei 6.803/80 (BRASIL, 1999a), abordando as diretrizes para o zoneamento industrial em áreas críticas de poluição, especialmente no que diz respeito a pólos petroquímicos, cloroquímicos, carboquímicos, e instalações nucleares

Com a Lei 6.938/81 (BRASIL, 1999b), que dispõe sobre a Política Nacional de Meio Ambiente, o Estudo de Impacto Ambiental tem sua funções ampliadas, ao ser elevado à categoria de instrumento da política nacional do meio ambiente.

Como afirmaram Lollo e Röhm (2005), o avanço fundamental na instituição do Estudo de Impacto Ambiental como mecanismo de gestão ambiental se deu com a Resolução CONAMA 01/86 (BRASIL) que estabeleceu "definições, as responsabilidades, os critérios básicos e as diretrizes gerais para o uso e implementação da Avaliação de Impacto Ambiental como um dos instrumentos da Política Nacional do Meio Ambiente". Esta não só definiu impacto ambiental, como descreveu os empreendimentos para os quais tais estudos são obrigatórios, e os mecanismos de realização de tais estudos. Esta Resolução criou ainda os Relatórios de Impacto Ambiental como expressão dos resultados dos Estudos de Impacto Ambiental.

A Resolução CONAMA 06/87 (BRASIL, 1987) estabeleceu regras especiais para o licenciamento ambiental de obras de grande porte relacionadas à geração de energia elétrica, subordinando o licenciamento prévio de tais atividades à elaboração de estudos de impacto ambiental.

Com a promulgação da Constituição Brasileira de 1988, o meio ambiente passa a ser definido como bem de uso comum do povo e ao poder público fica a responsabilidade de "exigir, na forma da lei, para instalação de obra ou atividade potencialmente causadora de degradação do meio ambiente, estudo prévio de impacto ambiental, a que se dará publicidade" dando nova força aos estudos de impacto ambiental (BRASIL, 1988).

Segundo Lollo e Röhm (2005), após a promulgação da Constituição Federal, praticamente todas as novas constituições dos estados brasileiros fizeram constar em seus textos, condições específicas para a realização de estudos de impacto ambiental para propostas de ocupação do meio e de uso de recursos naturais. Esses autores mencionaram que, com o intuito de disciplinar as Leis 6902/81 e 6938/81 que tratam, respectivamente da criação de Estações Ecológicas, das Áreas de Proteção Ambiental e da Política Nacional do Meio Ambiente, o Decreto 99274/90 (BRASIL, 
1990) propôs o uso dos estudos de impacto ambiental como fonte de informação para avaliações de alternativas técnicas em projetos e planos públicos e privados, cuja atividade possa gerar degradação ambiental.

A partir do início da década de 1990 houve grande desenvolvimento da legislação que trata do tema, possibilitando o surgimento de instrumentos legais (especialmente resoluções do CONAMA) responsáveis pelo detalhamento das informações relacionadas a estudos de impacto ambiental para os mais diversos ramos da atividade humana.

Pode-se considerar que a luta por uma legislação apropriada para a gestão urbana tem seu início com a apresentação da emenda popular da reforma urbana na Assembléia Nacional Constituinte, o que resultou no capítulo da política urbana da Constituição de 1988 (SAULE JR., 2001).

Tal legislação vigente, no entanto, trata essencialmente de propostas de ocupação que contemplam parcelas do terreno de dimensões significativas ou cujas atividades (industrial, geração de energia, e exploração de bens minerais) signifiquem evidente potencial de degradação ambiental, pouco se aplicando às ocupações urbanas relativamente comuns (como hospitais e estações rodoviárias, por exemplo), mas que representam alto potencial de geração de impactos no meio urbano.

Dessa maneira, os impactos decorrentes de ocupações urbanas de menor expressão espacial, mas que representam alterações significativas nas condições do meio ambiente urbano (tais como supermercados, shopping centers, grandes edifícios comerciais ou residenciais), necessitavam de alternativas apropriadas de caracterização e análise.

Sendo assim, há mais de uma década os meios técnico e jurídico, tanto do poder público como da iniciativa privada, vem procurando desenvolver mecanismos de identificação e análise de impactos em ambientes urbanos. Tal esforço resultou na proposição do Impacto de Vizinhança como instrumento para sanar ou reduzir esta dificuldade.

De acordo com Lollo e Röhm (2005), a proposição do EIV (Estudo de Impacto de Vizinhança) como instrumento de gestão ambiental urbana se deu devido à necessidade de um mecanismo de avaliação de impactos em condições particulares do meio urbano, porém também em um contexto histórico de evolução das propostas de avaliação de impactos na legislação brasileira. Para esses autores, o termo Impacto de Vizinhança foi criado para descrever um grupo específico de impactos ambientais que podem ocorrer em áreas urbanas em consequiência da implantação e operação de um determinado empreendimento e que se manifestam na área de influência do mesmo.

Houve necessidade de definir uma nova classe de impactos surgiu porque a legislação ambiental brasileira que trata dos impactos ambientais limitou a obrigatoriedade de realização de Estudos de Impacto Ambiental e elaboração de Relatórios de Impacto Ambiental a empreendimentos urbanos de dimensões significativas (grandes conjuntos habitacionais e aeroportos, por exemplo), ou típicos de áreas rurais ou suburbanas (rodovias, ferrovias, barragens, exploração de bens minerais, entre outros).

Como consequência da adoção desse novo enfoque, surgiu a necessidade de proposição de um mecanismo de análise dos impactos de vizinhança. Tal mecanismo se configurou na forma dos Estudos de Impacto de Vizinhança. Este compreende a identificação, valoração (se possível), e análise dos impactos de vizinhança previstos para uma determinada proposta de ocupação urbana. Para tanto, devem conter a caracterização do empreendimento, de sua área de influência, os impactos esperados, e as medidas mitigadoras e compensatórias previstas. Os resultados são apresentados em Relatórios de Impacto de Vizinhança.

A análise de relatórios de impacto de vizinhança elaborados no passado e da legislação que disciplina sua realização indicam que tais estudos consideram preferencialmente os impactos urbanísticos e os impactos na infraestrutura urbana previstos como decorrência da implantação do 
empreendimento. Dessa maneira percebe-se importância inegável do EIV como um dos instrumentos de ordenação territorial e controle de impactos voltado para o meio urbano.

\section{O ESTUDO DE IMPACTO DE VIZINHANÇA E A QUALIDADE DE VIDA URBANA}

A qualidade de vida constitui um tema de crescente relevância nas análises e nas políticas de planejamento e de gestão do território, em particular à escala das cidades. A forte competição existente entre os diferentes centros urbanos na captação de investimentos e de recursos humanos qualificados, associada a uma maior conscientização e exigência por parte dos cidadãos, fizeram com que diversos aspectos associados à qualidade de vida se tornassem preocupação central das administrações públicas nos níveis local, regional e nacional (SANTOS et al., 2009).

Ao mesmo tempo em que as cidades se afirmam como centros de riqueza e de poder, estas surgem como contextos espaciais em que se revelam marcadas por aspectos negativos associados às sociedades desenvolvidas tais como, a degradação ambiental, a exclusão social, a insegurança ou os congestionamentos de trânsito.

O conceito de qualidade de vida é um conceito abrangente no qual se interligam diversas abordagens e diversas problemáticas. Como já mencionado no inicio deste estudo, tal conceito surgiu na década de 1960 e estava diretamente relacionado com os sistemas de indicadores sociais, os quais se encontravam em fase de implementação e expansão. Este conceito vida surge em contraponto a visões mais economicistas que analisavam o crescimento econômico e o próprio desenvolvimento das sociedades exclusivamente com base em indicadores econômicos como, por exemplo, o PIB (Produto Interno Bruto).

Esses indicadores da riqueza produzida e/ou distribuída traduziam de forma global o crescimento econômico, mas não contemplavam diversos aspectos fundamentais que permitissem analisar o real progresso de uma sociedade. Questões tão decisivas como as da desigualdade na distribuição da riqueza produzida, do grau de satisfação das necessidades básicas da população, do nível de bem estar global, necessitavam de outros instrumentais de análise.

Além disso, discutia-se a questão da intervenção do Estado no funcionamento da sociedade, sendo fundamental a identificação das principais áreas que careciam de intervenção pública e das medidas que permitissem aferir as consequências das diversas ações empreendidas no sentido de sanar ou pelo menos amenizarem as deficiências detectadas (SANTOS et al., 2009).

Das diversas abordagens e problemáticas relacionadas com o conceito de qualidade de vida, decorrem três grandes perspectivas de análise. A primeira está relacionada com a distinção entre os aspectos materiais e imateriais da qualidade de vida. Os aspectos materiais dizem essencialmente respeito às necessidades humanas básicas, como, por exemplo, as condições de habitação, de abastecimento de água, do sistema de saúde, ou seja, aspectos de natureza essencialmente física e infraestrutural (SANTOS et al., 2009). Historicamente e para sociedades menos desenvolvidas, estas questões materiais eram decisivas ou pelo menos tinham uma focalização muito grande; hoje em dia, as questões imateriais mais ligadas ao ambiente, ao patrimônio cultural, ao bem estar, tornaram-se centrais.

A segunda perspectiva faz a distinção entre os aspectos individuais e os coletivos. Os componentes individuais mais relacionados com a condição econômica, a condição pessoal e familiar dos indivíduos, as relações pessoais, e as componentes coletivas mais diretamente relacionadas com os serviços básicos e os serviços públicos (SANTOS et al., 2009).

É possível considerar uma terceira perspectiva de análise, voltada para a distinção entre aspectos objetivos e subjetivos da qualidade de vida. Os primeiros seriam facilmente apreendidos por meio da definição de indicadores de natureza quantitativa, enquanto que os segundos remeteriam para a percepção subjetiva que os indivíduos têm da qualidade de vida e que é, 
claramente, diferente de pessoa para pessoa, e de estrato social para estrato social (SANTOS et al., 2009). Este último aspecto é de fundamental importância: os indicadores de qualidade de vida têm diferentes traduções, consoante a estrutura socioeconômica da população e, portanto, o mesmo indicador pode ser percebido de forma diferente por estratos socioeconômicos diferentes.

Estas três perspectivas de análise não são, obviamente, mutuamente exclusivas, mas pelo contrário interligam-se em grande medida. Os principais contributos teóricos para a abordagem da qualidade de vida refletem precisamente essa interdependência, conjugando os diversos níveis de análise referidos (SANTOS et al., 2009).

Para Maslow 1954 apud Ribeiro e Vargas (2001) a definição de qualidade de vida, sustentase na teoria das necessidades básicas. Segundo esses autores, as necessidades humanas apresentamse hierarquicamente da seguinte forma: necessidades fisiológicas: fome, sono; necessidades de segurança: estabilidade, ordem; necessidades de amor e pertinência: família, amigos; necessidades de estima: respeito, aceitação; necessidades de auto-atualização e capacitação.

Para Liu apud Lo e Faber (1997) a qualidade de vida inclui as dimensões psicológicas e sociológicas, habitação adequada; a participação em atividades culturais, de entretenimento, tempo para leitura; satisfação nas relações interpessoais e um bom convívio familiar; o conhecimento e os recursos para se adaptar aos tempos de mudança, a igualdade de oportunidades para influenciar na direção e na velocidade das mudanças.

A Unidade de Pesquisa de Qualidade de Vida da Universidade de Toronto considera a qualidade de vida como o grau em que uma pessoa desfruta de possibilidades importantes para sua vida. As possibilidades resultam das oportunidades e limitações que cada pessoa tem em sua vida e reflete a interação de fatores pessoais e ambientais. O usufruto tem duas componentes: a experiência de satisfação e posse ou realização. Os três maiores domínios identificados são: ser, pertencer e tornar-se, conforme a Tabela 1 (GDRC, 2002 apud MORATO et al., 2006).

Apesar da dificuldade de se definir o termo qualidade de vida, devido principalmente à subjetividade implícita, é notória a contribuição dos instrumentos de avaliação ambiental para a manutenção da qualidade ambiental tanto no meio natural, quanto no meio urbano.

O EIV, ao diagnosticar e propor possíveis ações para solucionar ou mitigar os impactos que um empreendimento poderá causar em sua vizinhança, proporcionará condições urbanas mais adequadas ao desenvolvimento local, promovendo qualidade de vida [assumida aqui como as necessidades básicas mencionadas anteriormente, seguindo a concepção de Maslow 1954 apud Ribeiro e Vargas (2001) para a população.

Tabela 1 - Domínios da Qualidade de Vida da Unidade de Pesquisa de Qualidade de Vida da Universidade de Toronto, Canadá. Fonte: GDRC, 2002 apud Morato et al. (2006).

\begin{tabular}{|c|c|c|}
\hline Ser (Being) & Pertencer (Belonging) & Tornar-se (Becoming) \\
\hline $\begin{array}{l}\text { O domínio do ser inclui } \\
\text { aspectos básicos de quem alguém é } \\
\text { e tem três subdomínios. O ser } \\
\text { físico, que inclui aspectos de saúde } \\
\text { física, higiene, pessoas, nutrição, } \\
\text { exercícios, roupas e aparência } \\
\text { física. O ser psicológico inclui } \\
\text { saúde psicológica da pessoa, } \\
\text { sentimentos, avaliações sobre si } \\
\text { mesmo e autocontrole. O ser } \\
\text { espiritual reflete valores pessoais, } \\
\text { padrões pessoais de conduta, e } \\
\text { comportamento espiritual, que } \\
\text { podem ou não estar associados com } \\
\text { organizações religiosas. }\end{array}$ & $\begin{array}{l}\text { O pertencer inclui a adaptação da } \\
\text { pessoa com seus ambientes em três } \\
\text { subdomínios. O pertencer físico é definido } \\
\text { como as ligações da pessoa com seu } \\
\text { ambiente físico, como sua casa, seu local de } \\
\text { trabalho, vizinhança, escola ou } \\
\text { comunidade. O pertencer social inclui as } \\
\text { ligações com o ambiente social e incluem } \\
\text { os sentimentos de aceitação pelos outros: } \\
\text { família, amigos, colaboradores, vizinhos e } \\
\text { comunidade. O pertencer comunitário } \\
\text { representa o acesso a recursos normalmente } \\
\text { disponíveis para os membros da } \\
\text { comunidade, como renda adequada, } \\
\text { serviços sociais e de saúde, emprego, } \\
\text { programas educacionais e recreacionais e } \\
\text { atividades comunitárias. }\end{array}$ & $\begin{array}{l}\text { O tornar-se diz respeito a seguir } \\
\text { objetivos propostos para realizar } \\
\text { objetivos pessoais, expectativas e desejos. } \\
\text { O tornar-se prático descreve as ações do } \\
\text { dia-a-dia, como atividades domésticas, do } \\
\text { trabalho, da escola ou atividades } \\
\text { voluntárias, tendo em vista as } \\
\text { necessidades sociais e para a saúde. } \\
\text { O tornar-se lazer, inclui } \\
\text { atividades que promovem o relaxamento } \\
\text { e a redução do estresse. Inclui jogos de } \\
\text { castas, caminhadas pela vizinhança, } \\
\text { visitas à família, ou atividades de maior } \\
\text { duração como férias e feriados. O tornar- } \\
\text { se crescimento promove atividades que } \\
\text { aperfeiçoam o conhecimento e a } \\
\text { experiência. }\end{array}$ \\
\hline
\end{tabular}


A principal vantagem do EIV como instrumento provedor de qualidade de vida urbana em relação aos outros instrumentos está em sua abrangência, pois além de estudar os impactos de um dado empreendimento, também está focado nos impactos de vizinhança que a cadeia produtiva atraída por tal empreendimento irá gerar, além de ser um instituto voltado para o meio urbano.

\section{CONSIDERAÇÕES FINAIS}

A preocupação com questões ambientais é crescente no Brasil, e muitas vezes vê-se a sociedade posicionar-se perante o Poder Público, exigindo deste, postura ambientalmente responsável, inclusive quanto à implementação de mecanismos coercitivos à degradação ambiental. A importância da preservação e da recuperação do meio ambiente tem motivado a elaboração de legislação específica sobre o assunto, bastante ampla, que denota grande preocupação com os impactos advindos de atividades potencialmente danosas ao meio ambiente. A fim de avaliar corretamente os riscos embutidos no desenvolvimento dessas atividades, instituíram-se os estudos de impacto ambiental, em distintas esferas e aplicabilidades.

Mais recentemente, refletindo a consciência de que o meio urbano é o ambiente com o qual os seres humanos mais interagem, evidenciou-se que a qualidade de vida nas cidades está diretamente associada ao controle das atividades nelas desenvolvidas. É possível reverter cenários desfavoráveis pela implementação de mecanismos de gestão urbana. Um destes instrumentos é o Estudo de Impacto de Vizinhança (EIV). Trata-se de um instrumento contemporâneo, que tem sua matriz no cumprimento da função social da propriedade, mas cuja regulamentação depende de lei municipal específica.

Muito embora a elaboração de estudos de impacto ambiental seja uma prática bastante recorrente, o EIV ainda é um grande desconhecido, e muitas dúvidas pairam sobre sua elaboração. Não é incomum que planejadores urbanos não tenham familiaridade com este instrumento de importância para a saúde do ambiente urbano e das relações sociais nele desenvolvidas. O EIV carece da visibilidade de outros estudos ambientais, em especial o EIA/RIMA, até para que fique evidente sua abrangência, delimitação e adequabilidade.

Recomenda-se aos municípios, exemplificativamente, que sejam sujeitos ao EIV grandes empreendimentos geradores de fluxos importantes de pessoas e veículos, como hipermercados, centros de compras e lazer, hospitais, aeroportos, grandes loteamentos urbanísticos, bem como atividades desenvolvidas no meio urbano causadoras de poluição visual, sonora e que causem possíveis emanações radioativas, como as torres e estações de telefonia celular. Também devem ser considerados os empreendimentos e atividades propostos em área de maior sensibilidade, ou próximos a estas, como os sítios históricos e locais de especial interesse ambiental (SAMPAIO, 2005).

O EIV deve fazer a demonstração da compatibilidade do empreendimento com a capacidade das redes de infraestrutura urbana, sistema de transporte público, paisagem urbana da vizinhança, atividades humanas vizinhas e recursos naturais remanescentes da urbanização, principalmente solo, ar, água, silêncio, clima, vegetação e fauna.

Por fim, espera-se que o EIV promova a redescoberta do vínculo do cidadão com o espaço urbano onde vive, mediante a discussão das funções urbanas, dos fatores degradadores da cidade, das relações sociais e da manutenção ou mesmo retomada dos índices de qualidade de vida, fazendo o indivíduo entender-se como parte integrante do ecossistema e, portanto, responsável pela sustentabilidade do meio ambiente urbano. 


\section{AGRADECIMENTOS}

Agradecemos a Fundação de Amparo à Pesquisa do Estado de São Paulo - FAPESP pela concessão de bolsa de estudos em nível de mestrado, sob o processo $n^{\circ}$ 2009/11160-3.

\section{REFERÊNCIAS}

BARCELLOS, P.F.P.; BARCELLOS, L.F.P. Planejamento urbano sob perspectiva sistêmica: considerações sobre a função social da propriedade e a preocupação ambiental. Revista da FAE, Curitiba, v.7, n.1, p.129-144, 2004. Disponível em: <www.ecoeco.org.br/conteudo/publicacoes/ encontros/v_en/.../2.pdf > Acesso em 10/05/2010.

BRASIL. Ministério do Meio Ambiente, Conselho Nacional de Meio Ambiente, CONAMA. Resolução CONAMA no 1, de 23 de janeiro de 1986. - In: Resoluções, 1986. Disponível em: <http://www.mma.gov.br> Acesso em: 12/03/2010.

BRASIL. Ministério do Meio Ambiente, Conselho Nacional de Meio Ambiente, CONAMA. Resolução CONAMA n. 6, de 16 de setembro de 1987. In: Resoluções, 1987. Disponível em: <http://www.mma.gov.br> Acesso em: 12/03/2010.

BRASIL. Constituição de 1988. Constituição da República Federativa do Brasil: promulgada em 5 de outubro de 1988. Organização do texto: Juarez de Oliveira. 4. ed. São Paulo: Saraiva, 1990. 168 p. (Série Legislação Brasileira).

BRASIL. Decreto n. 99274/90 de 6 de junho de 1990. Regulamenta a Lei nº 6.902, de 27 de Abril de 1981, e a Lei n ${ }^{\circ}$ 6.938, de 31 de Agosto de 1981, que dispõem, respectivamente, sobre a criação de Estações Ecológicas e Áreas de Proteção Ambiental e sobre a Política Nacional do Meio Ambiente, e dá outras providências. Diário Oficial da União, Brasília, edição de 7 de junho, 1990.

BRASIL. Lei n. 6803, de 2 de julho de 1980. Dispõe sobre as diretrizes básicas para o zoneamento industrial nas áreas críticas de poluição, e dá outras providências. Legislação Brasileira de

Resíduos Sólidos e Ambiental Correlata: Caderno Legislativo 004/99, Brasília, v. 1, p. 291-294, 1999a.

BRASIL. Lei n. 6938, de 31 de agosto de 1981. Dispõe sobre a Política Nacional do Meio Ambiente, seus fins e mecanismos de formulação e aplicação, e dá outras providências. Legislação Brasileira de Resíduos Sólidos e Ambiental Correlata: Caderno Legislativo 004/99, Brasília, v. 1, 297-305, 1999b.

BRASIL. Lei 10.257, de 10 de Julho de 2001. Regulamenta os arts. 182 e 183 da Constituição Federal, estabelece as diretrizes gerais da política urbana e dá outras providências. Diário Oficial da União, Brasília, edição de 11 de julho de 2001.

BRITO, L.G. de; GÓIS, V.S. de. A cidade de Natal e o Estudo de Impacto de Vizinhança. Revista Constituição e Garantia de Direitos vol. 2, n. 1, 16p. 2008. Revista Eletrônica do Programa de Pós-Graduação em Direito da Universidade Federal do Rio Grande do Norte. Disponível em: <www.ccsa.ufrn.br/ojs/ index.php/PPGD/ article/view/59/> Acesso em 14/04/2010. 
DEÁK, C. Dicionário Eletrônico. Departamento de Projeto Faculdade de Arquitetura e Urbanismo Universidade de São Paulo, 2010. Disponível em: http://www.usp.br/fau/ docentes/depprojeto/c_deak/CD/4verb/planejamento-urb/index.html Acesso em: 19/05/2010.

FERRAZ, L.C.. Cubatão (in) sustentável: Cidade continua a ostentar o título de campeã brasileira em poluição. Revista Eletrônica Meio-Ambiente, Cubatão, 2p., 2006. Disponível em: <http://www.novomilenio.inf.br/real/ed155o.htm>. Acesso em: 15/04/2010.

FLORIANO, E.P. Planejamento Ambiental. Caderno Didático, nº6. 1 Ed. Santa Rosa, 54p., 2004.

LO, C.P.; FABER, B.J. integration of landsat thematic mapper and census data for quality of life assessment. Remote Sensing of Environment, n.62, p.143-157, 1997.

LOLLO, J.A; RÖHM, S.A. Aspectos negligenciados em Estudos de Impacto de Vizinhança. Estudos Geográficos, Rio Claro, v. 3, n. 2, p. 31-45, 2005.

MORAES, I.R. de . O Processo de Urbanização e o Estudo de Impacto de Vizinhança. In: Conselho Nacional de Pesquisa e Pós-Graduação em Direito, CONPEDI. Desafios do Direito Urbanístico, 2007. 12p. Disponível em: <http://www.miniweb.com.br/> Acesso em: 14/04/2010.

MORATO, R.G.; KAWAKUBO, F.S.; MARTINES, M.R.; FERREIRA, R.V.; LUCHIARI, A. Mapeamento da Qualidade de Vida Urbana no Município de1 Osasco/SP. III Encontro Associação Nacional de Pós-Graduação e Pesquisa em Ambiente e Sociedade. Centro de Convenções Israel Pinheiro. Brasília - Distrito Federal - Brasil, 24p., 2006. Disponível em: www.anppas.org.br/encontro.../TA612-07032006-195325.DOC>. Acesso em: 19/04/2010.

MOREIRA, A.C.M.L. Conceitos de ambiente e impacto ambiental aplicados ao meio urbano. São Paulo: Faculdade de Arquitetura e Urbanismo, Universidade de São Paulo, São Paulo. 1999, 6p. (Material didático da disciplina de pós-graduação AUP 5861 - Políticas públicas de proteção do ambiente urbano). 1999. Disponível em: <http://www.usp.br/ fau/docentes/depprojeto/ a_moreira/producao/producao.htm>. Acesso em 15/04/2010.

RIBEIRO, H.; VARGAS, H. C. Qualidade Ambiental Urbana: Ensaio de uma Definição. In: VARGAS, H. C.; RIBEIRO, H. (org.) Novos Instrumentos de Gestão Ambiental Urbana. São Paulo: Edusp, 2001, p.13-19.

RODRIGUES, L.P.O.S; FILHO, N.B.B. O controle das atividades urbanas e as mudanças climáticas: enfoque sobre a futura região metropolitana de São Luís do Maranhão. In: Caderno de Pesquisas, Universidade Federal do Maranhão, São Luís, v. 18, n. 1, jan./abr. 2011, 14p. Disponível em: < http://www.pppg.ufma.br/cadernosdepesquisa/uploads/files/Artigo\%203\%2822 \%29.pdf $>$. Acesso em: 15/01/2011.

SABOYA, R. O surgimento do planejamento urbano. Revista Eletrônica Urbanidades, v.01, 2p., 2008. Disponível em: <http://urbanidades.arq.br/2008/03/o-surgimento-do-planejamento-urbano/> Acesso em: 14/04/2010.

SAMPAIO, L. Estudo de Impacto de Vizinhança: sua pertinência e a delimitação de sua abrangência em face de outros estudos ambientais. Monografia de Especialização em Direito 
Ambiental e Desenvolvimento Sustentável, Centro de Desenvolvimento Sustentável. Universidade de Brasília, Brasília-DF, 2005, 65p.

SANTOS, L.D.; MARTINS, I. A Qualidade de Vida Urbana - O Caso da Cidade do Porto. Investigação. Revista Trabalhos em Curso, n.116, 25p, 2002. Disponível em: <http://www.scielo.br/scieloOrg/php/reflinks.php?refpid=S1414-753X2006000200007 00014\&pid=S1414-753X 2006000200007\&lng=en> Acesso em: 10/05/2010.

SANTOS, L.D.; MARTINS, I.; BRITO, P. O conceito de qualidade de vida urbana na perspectiva dos residentes na cidade do Porto. Faculdade de Economia da Universidade do Porto. Centro de Estudos Macroeconómicos e Previsão. Gabinete de Estudos e Planeamento Câmara Municipal do Porto, 2009. 14p. Disponível em: <www.apdr.pt/siteRPER/numeros/ RPER09/art01_rper9.pdf> Acesso em: 16/04/2010.

SAULE JR., N. Nota política sobre os vetos do estatuto e as conquistas da reforma urbana. 16 de julho de 2001. Disponível em <http://polis.org.br/publicacoes/dicas/>. Acesso em 29 de agosto de 2004.

VERONA, J.A. Geografia do crime e contribuição ao planejamento sócio - espacial do município de Jundiaí-SP. Tese de Doutorado em Geografia. Departamento de Geografia, Instituto de Geociências e Ciências Exatas Campus de Rio Claro. Universidade Estadual Paulista, Rio Claro, 2006, 167p.

ZIBORDI, M.S.; CARDOSO, J.L. Análise tecnológica para gestão da agropecuária na bacia hidrográfica do Rio Mogi-Guaçu. In: XLIII Congresso da Sociedade Brasileira de Economia e Sociologia Rural, Ribeirão Preto, 2005,16p. 